\title{
Microbiological Profile of Ventilator Associated Pneumonia
}

\author{
Shashikant ${ }^{1}$, Jayaraj Patil ${ }^{2}$ \\ ${ }^{1}$ Senior Resident, Department of Pediatrics, GIMS, Gadag, Karnataka, ${ }^{2}$ Assistant Professor, Department of Pediatrics, GIMS, Gadag, Karnataka.
}

\section{Abstract}

Background: Nosocomial gram negative bacterial pneumonias develop in hospitalized and are due to changes in the bacterial flora. Colonization of the upper respiratory tract by gram negative bacilli is mediated by alterations in the surface properties of the epithelial cells. In healthy individuals a film of fibronectin covers the epithelium lining the mucosa of the mouth and oropharynx and prevents the Gram-negative bacteria from adhering to the epithelial cells. This protective coating is lost in very ill individuals, so that pathogenic Gram- negative organisms adhere to receptors present on epithelial cells of the mucosa and soon colonize it. Subjects and Methods: The children aged between 1 month and 16 years who are included in this study are those who are on mechanical ventilator for more than 48 hours. All children who are admitted in PICU and mechanically ventilated for more than 48 hours as per definition in inclusion criteria are investigated clinically, radiologically and bacteriologically to determine presence of pneumonia and isolate causative microorganism. Results: Common organism isolated ET tip culture of patients studied was Klebsiella 29 (19.3\%), followed by Pseudomonas 6(4\%), E.coli6 (4\%), MRSA 6(4\%). Most common organism isolated in urine culture of patients studied was E.coli 8(5.4\%) followed by Klebsiella 3(2\%). Conclusion: The common organisms isolated in blood culture and ET tip culture were Klebsiella, Pseudomonas aerogenosa and E. coli.

Keywords: Ventilator Associated Pneumonia, Gram-Negative Bacteria, MRSA.

Corresponding Author: Dr. Jayaraj Patil, Assistant Professor, Department of Pediatrics, GIMS, Gadag, Karnataka.

Received: January 2019

Accepted: February 2019

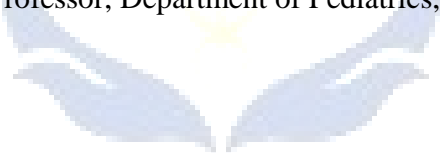

\section{Introduction}

In Asia, most pathogens are multidrug-resistant. Two studies reported differences in the microbiologies of early-onset and late-onset nosocomial pneumonia among children. Group B streptococci were most commonly isolated from infants with maternally acquired pneumonia (31.8\%), while these organisms were rarely isolated in cases of late-onset pneumonia (1.3\%). The frequency of Staphylococcus aureus increased from $2.4 \%$ of maternally acquired cases to $18.7 \%$ of non-maternally-acquired cases of pneumonia and Pseudomonas aeruginosa frequency increased from $2.9 \%$ of maternally acquired cases to $12.9 \%$ of non-maternallyacquired cases of pneumonia. ${ }^{[1,2]}$

There appears to be three key risk factors that influence the type of infection in VAP, the underlying disease condition, the duration of mechanical ventilation before the onset pneumonia and prior antibiotic exposure. Pseudomonas aerugenosa \& other multidrug resistant pathogens are common in patients who have previously received antibiotics, steroids or ventilation for more than 6 days (late onset) \& are associated with higher mortality rate. There is an enormous impact of antimicrobial agents on the organisms responsible for NP. The organisms of the normal oropharyngeal flora virtually disappear \& are being replaced by gram negative bacilli in the patients who are on prior antibiotics and in those who are seriously ill.
For any infection to occur, there must be an interplay of 3 factors i,e : impaired host defence, access of pathogenic bacteria in sufficient numbers and the virulence of the organism. ${ }^{[3]}$

Nosocomial gram negative bacterial pneumonias develop in hospitalised and are due to changes in the bacterial flora. Colonization of the upper respiratory tract by gram negative bacilli is mediated by alterations in the surface properties of the epithelial cells. In healthy individuals a film of fibronectin covers the epithelium lining the mucosa of the mouth and oropharynx and prevents the Gram-negative bacteria from adhering to the epithelial cells. This protective coating is lost in very ill individuals, so that pathogenic Gram- negative organisms adhere to receptors present on epithelial cells of the mucosa and soon colonize it. The number of these bacterial receptors on both upper and lower airway epithelial cells is increased in many illnesses. The risk factors responsible for oropharyngeal colonisation with gram negative bacteria include neutropenia, prior antibiotic therapy, alcoholism, azotemia, coma, diabetes, serious illness, hypotension, intubation, smoking, surgery and neutralization of gastric acid. ${ }^{[4]}$

Of the potential routes of bacterial entry, micro aspiration of a small volume of oropharyngeal secretions previously colonized with pathogenic bacteria is most common. Micro aspiration is reported even in healthy people during sleep, but it is the presence of pathogenic bacteria which are able to over helm the lower respiratory tract defences that is most 
important in the development of pneumonia.

The incidence of aspiration increases when the gag reflex is impaired, if there is an alteration in level of consciousness, when certain devices such as nasogastric tube or endotracheal tubes (ET) are used or if esophageal diseases are present.

Among mechanically ventilated patients additional routes of entry exist. The ET tubes bypass host defenses above the vocal cords and impairs lower respiratory tract defenses such as cough and mucociliary clearance. Contaminated secretions can pool above the inflated ET cuff and are not easily removed by suctioning. The secretions can leak around the ET cuff and directly enter the lower respiratory tract when there are changes in airway caliber during swallowing and breathing. ${ }^{[5]}$

The acid within the stomach serves as a major deterrent to bacteria swallowed in the saliva. If gastric acidity is suppressed by the use of antacids and $\mathrm{H} 2$ - antagonists, the bacteria within the stomach survive, multiply and soon colonize the upper gastrointestinal tract. Gastric contents laden with Gram- negative bacteria could easily regurgitate and be aspirated into the lungs, causing aspiration pneumonia. This is particularly frequent in obtunded patients, sedated patients or following a large vomit.

Rarely infected emboli from a septic thrombophlebitis can lead to septic infarcts within the lung. Catheter related sepsis or any other source of sepsis can cause bacteremia with haematogenous spread of infection into the lungs, causing pneumonia. $^{[5]}$

Contaminated respiratory equipment (nebulizers, humidifiers, ventilator tubing etc) are a source of infected aerosols. Infected particles 3-5 microns in size can be deposited into the terminal bronchioles and alveoli, thereby causing a lower respiratory tract infection. ${ }^{[5]}$

Lack of aseptic precautions during suction of tracheobronchial secretions, either through an endotracheal tube or tracheostomy is an important cause of lower respiratory tract infection. Medical staff or respiratory therapy equipment harbours pathogenic flora and bacteria can be directly inoculated into tracheobronchial tree. ${ }^{[6]}$

In this closed milieu the major reservoir of nosocomial organisms is the infected or colonized patient. Most bacteria, many viruses, and possibly even fungi are spread primarily via the hands of the medical, paramedical and nursing staff. Aspiration of infected pharyngeal and mouth secretions, exposure to invasive devices and procedures, surgery, impairment of immune mechanisms or overwhelming illnesses amplify colonization and vulnerability to nosocomial infections and promote their easy transmission. In most patients, antibiotic use promotes sooner or later antibiotic resistance to a number of organisms that prevail in a particular ICU. These resistant organisms contaminate the whole closed environment of the ICU: they can contaminate the curtains, the walls, floor and ceilings, the side tables, the wash basins and the soap dishes, the detergents used as antiseptics, and the clothing and hands of the ICU staff. Bacteria from colonized or infected patients can also be perpetuated in urine bottles, bedpans, commodes, respiratory

therapy equipment, ventilators, and chamber domes of transducers used in hemodynamic monitoring and in bronchoscopes or other endoscopes.

In short, the closed milieu of the ICUs provides an environment that is as conducive to the growth and preservation of resistant organisms.

\section{Subjects and Methods}

\section{Sample Size}

150 children aged between 1 month and 16 years

\section{Sampling procedure}

Consecutive patients in pediatric intensive care unit on mechanical ventilator who developed pneumonia fulfilling inclusion criteria were studied.

\section{Inclusion criteria}

- The children aged between 1 month and 16 years who are included in this study are those who are on mechanical ventilator for more than 48 hours

\section{Exclusion Criteria}

- Patients who developed respiratory infections in less than 48 hours of mechanical ventilation, those who are discharged from PICU in less than 48 hours or died within 48 hours are excluded.

- Children of Parents who have not given consent

\section{Methods of Study}

All children who are admitted in PICU and mechanically ventilated for more than 48 hours as per definition in inclusion criteria are investigated clinically, radiologically and bacteriologically to determine presence of pneumonia and isolate causative microorganism. The study also considered the presence of comorbid conditions like $\mathrm{CP}$, CHD, hematological disorders, SEIZURE disorders.

Outcome variable in development of VAP depends on following factors like age, sex, clinical signs and symptoms, comorbid illness, organism isolated, use of medical devices like RT tube and duration of ventilation etc.

\section{Results}

Table 1: Organism in ET tip culture of patients studied

\begin{tabular}{|l|l|l|l|}
\hline \multirow{2}{*}{$\begin{array}{l}\text { Organism in ET tip } \\
\text { culture }\end{array}$} & Gender & Total \\
\cline { 2 - 3 } & Female & Male & \\
\hline Nil & $46(63.9 \%)$ & $49(62.8 \%)$ & $95(63.3 \%)$ \\
\hline Klebsiella & $17(23.6 \%)$ & $12(15.4 \%)$ & $29(19.3 \%)$ \\
\hline $\begin{array}{l}\text { Gram non } \\
\text { fermenters }\end{array}$ & $4(5.6 \%)$ & $1(1.3 \%)$ & $5(3.3 \%)$ \\
\hline E.coli & & & \\
\hline MRSA & $1(1.4 \%)$ & $5(6.4 \%)$ & $6(4 \%)$ \\
\hline Pseudomonas & $1(1.4 \%)$ & $5(6.4 \%)$ & $6(4 \%)$ \\
\hline Non candida Albicans & $2(2.8 \%)$ & $4(5.1 \%)$ & $6(4 \%)$ \\
\hline MSSA & $0(0 \%)$ & $0(0 \%)$ & $0(0 \%)$ \\
\hline Enterobacter & $0(0 \%)$ & $0(0 \%)$ & $0(0 \%)$ \\
\hline Total & $1(1.4 \%)$ & $2(2.6 \%)$ & $3(2 \%)$ \\
\hline $\mathrm{P}=0.181$ & $72(100 \%)$ & $78(100 \%)$ & $150(100 \%)$ \\
\hline
\end{tabular}




\section{Shashikant \& Patil; Micrabialagical Prafile of Ventilatar Assaciated Pneumania}

Common organism isolated ET tip culture of patients studied was Klebsiella $29(19.3 \%)$,followed by Pseudomonas 6 (4\%), E.coli 6 (4\%), MRSA 6 (4\%).

Table 2: Organism grown in Blood culture of patients studied.

\begin{tabular}{|l|l|l|l|}
\hline \multirow{2}{*}{$\begin{array}{l}\text { Organism grown in } \\
\text { Blood culture }\end{array}$} & Gender & \multicolumn{2}{|l|}{ Total } \\
\cline { 2 - 3 } Nil & Female & Male & \\
\hline Klebsiella & $44(61.1 \%)$ & $51(65.4 \%)$ & $95(63.3 \%)$ \\
\hline $\begin{array}{l}\text { Gram ve non } \\
\text { fermenters }\end{array}$ & $12(16.7 \%)$ & $9(11.5 \%)$ & $21(14 \%)$ \\
\hline E.coli & $7(9.7 \%)$ & $0(0 \%)$ & $7(4.7 \%)$ \\
\hline MRSA & $1(1.4 \%)$ & $2(2.6 \%)$ & $3(2 \%)$ \\
\hline Pseudomonas & $2(2.8 \%)$ & $7(9 \%)$ & $9(6 \%)$ \\
\hline Non candida Albicans & $2(2.8 \%)$ & $4(5.1 \%)$ & $6(4 \%)$ \\
\hline MSSA & $1(1.4 \%)$ & $2(2.6 \%)$ & $3(2 \%)$ \\
\hline Enterobacter & $2(2.8 \%)$ & $1(1.3 \%)$ & $3(2 \%)$ \\
\hline Total & $1(1.4 \%)$ & $2(2.6 \%)$ & $3(2 \%)$ \\
\hline
\end{tabular}

$\mathrm{P}=0.130$

Most common organism isolated in blood culture of patients studied was Klebsiella 21(14\%), followed by MRSA 6 (4\%), Gram negative non fermenters 7(4.7\%),Pseudomonas6 (4\%), E.coli 3 (2\%).

Table 3: Organism grown in Urine culture of patients studied

\begin{tabular}{|l|l|l|l|}
\hline \multirow{2}{*}{$\begin{array}{l}\text { Organism grown } \\
\text { in Urine culture }\end{array}$} & Gender & Total \\
\cline { 2 - 3 } Nil & Female & Male & \\
\hline Klebsiella & $66(93 \%)$ & $70(92.1 \%)$ & $136(92.5 \%)$ \\
\hline E.coli & $0(0 \%)$ & $3(3.9 \%)$ & $3(2 \%)$ \\
\hline Total & $5(7 \%)$ & $3(3.9 \%)$ & $8(5.4 \%)$ \\
\hline
\end{tabular}

$\mathrm{P}=0.194$

Most common organism isolated in urine culture of patients studied was E.coli 8(5.4\%) followed by Klebsiella 3 (2\%).

\section{Discussion}

Table 4: Micro Organisms Isolated In ET Tip Culture of VAP
Patients In Comparison With Other Studies
\begin{tabular}{|l|l|}
\hline Study & Micro Organisms Isolated \\
\hline Present study (N=150) & Klebsiella (32.8\%) \\
& Pseudomonas (7.8\%) \\
& Gram -ve non fermenters (7.8\%) \\
& MRSA (7.8\%) \\
\hline $\begin{array}{l}\text { Muhammad Haroon Hamid et } \\
\text { al7(N=92) }\end{array}$ & Pseudomonas (07\%) \\
& E coli (04\%) \\
\hline \multirow{3}{*}{ Noyal Mariya Joseph et al8 (N=206) } & Pseudomonas \\
& $(21.3 \%)$ \\
& Acinetobacter \\
& $(21.3 \%)$ \\
& Staphylococcus aureus (14.9\%) \\
\hline Ronald N. Jones et al9(N=128) & MRSA(47.1\%) \\
& Pseudomonas species (18.4\%) \\
& Klebsiella species (7\%) \\
& Haemophilus species (5.6\%) \\
\hline
\end{tabular}

In present study most common organism isolated in ET tip culture in VAP patients was Klebsiella(32.8\%) followed by
Pseudomonas aerogenosa $(7.8 \%)$, Gram negative non fermenters $(7.8 \%)$ and Staphylococcus aureus (7.8\%) as compared to previous studies Noyal Mariya Joseph et al which showed Pseudomonas aeruginosa $(21.3 \%)$ and Acinetobacter baumannii (21.3\%) are more common organisms followed by Staphylococcus aureus (14.9\%). And other studies in USA showed MRSA (47.1\%) followed by Pseudomonas aerogenosa(18.4\%) and Klebsiella (7\%) as common microorganisms isolated in ET tip of VAP patients . This difference in results can be attributed to different ICU setups, hospital flora and training of nurses and asepsis protocols and antibiotic policy followed by hospital.

Table 5: Micro Organisms Isolated In Blood Culture of VAP Patients In Comparison With Other Studies

\begin{tabular}{|l|l|}
\hline Study & $\begin{array}{l}\text { Most Common Organisms } \\
\text { Isolated }\end{array}$ \\
\hline Present study (N=150) & Klebsiella (31\%) \\
& MRSA (10.9\%) \\
& Pseudomonas (7.8\%) \\
Gram -ve non fermenters (5\%)
\end{tabular}

In present study most common organism isolated in blood culture in VAP patients was Klebsiella(31\%) followed by Staphylococcus aureus,(10.9\%) Pseudomonas aeruginosa (7.8\%), Gram negative non fermenters $(6 \%)$ and as compared to previous studies Muhammad Haroon Hamid et al62 which shows Pseudomonas aeruginosa (15.3\%) followed by Klebsiella(5\%) and E.coli $(2.3 \%)$ are more common organisms isolated. And other studies Elizabeth Foglia et al showed Pseudomonas (38.4\%) followed by Acinetobacter Proteii (23\%) and Klebsiella (23\%) as most common organism isolated in of VAP patients. This difference in results can be attributed to different group of patients studied, method of collection of sample ,culture medias, different ICU set ups ,hospital flora and training of nurses and asepsis protocols, and antibiotic policy followed by hospital.

\section{Conclusion}

The common organisms isolated in blood culture and ET tip culture were Klebsiella, Pseudomonas aerogenosa and E. coli. 


\section{Shashikant \& Patil; Micrabialagical Prafile of Ventilatar Assaciated Pneumania}

\section{References}

1. Ewig S, Bauer T, Torres A. The pulmonary physiology in critical care :Nosocomial pneumonia Thorax 2002:57:366-371

2. Kollef MH. The prevention ventilator-associated pneumonia.;N Eng J Med. 1999:340:8:627-634.

3. Trouillet JL, Chastre J, Vaugnat A, JOLY-Guillou ML, Combaux D. Dombret MC and Gibert C; Ventilator- associated pneumonia caused by potentially drung resistant bacteria. Am J respire and Critical Care Med 1998:157:531-539.

4. Fagon JY, Chastre J, Hance AJ, Montravrs P, Novara A, Gibert C. Nosocomial pneumonia in ventilated patients: a cohort study evaluating attributable mortality and hospital stay. Am J Med 1993:94:281-228

5. Deborah C, Gordon G, John M, David L Hugh F, Richard H; A comparison of sucralfate and ranitidine for the prevention of upper gastrointestinal bleeding in patients requiring mechanical ventilation. N Engl J MED 1998: 791-797

6. Sanchez GM, Cambronero GJ. Lopez DJ. Cerda EC. Blasco J. Miguel A et al. Effectiveness and cost of selection decontamintion of the digestive tract in critically ill intrubated patients. A randomized.
Double-blind, placebo controlled, multicentre trial. Am J Respir Crit Care Med. 1998: 158:908-916

7. Muhammad Haroon Hamid, Muhammad Akbar Malik, Jawad Masood, Ahmed Zia and Tahir Masood Ahmad; VentilatorAssociated Pneumonia in Children; the College of Physicians and Surgeons Pakistan 2012, Vol. 22 (3): 155-158

8. Noyal Mariya Joseph, Sistla Sujatha , Dutta Tarun Kumar, Ashok Shankar Badhe, Desdemona Rasit, Ventilator-associated pneumonia in a tertiary care hospital in India: role of multi-drug resistant pathogens ;J,infect.diseasedev ctries,2009,3(10)/771-772

9. Ronald N. Jones; Microbial Etiologies of Hospital-Acquired Bacterial Pneumonia and Ventilator-Associated Bacterial Pneumonia, JMI Laboratories, North Liberty

10. Dr. Tripathi, Shalini , Dr. Malik G. K., Dr. Jain Amita and Dr. Kohli Neera Study of Ventilator Associated Pneumonia in Neonatal Intensive Care Unit: characteristics, risk factors and outcome; Internet Journal of Medical Update 2010 January;5(1):12-19

11. Foglia Elizabath,MaAE. ;Ventilator-Associated Pneumonia In Neonatal And Pediatric Intensive Care Unit Patients. Clinical Microbiology Reviews. 2007;20(3):409 25

Copyright: (C) the author(s), 2019. It is an open-access article distributed under the terms of the Creative Commons Attribution License (CC BY 4.0), which permits authors to retain ownership of the copyright for their content, and allow anyone to download, reuse, reprint, modify, distribute and/or copy the content as long as the original authors and source are cited.

How to cite this article: Shashikant, Patil J. Microbiological Profile of Ventilator Associated Pneumonia. Asian J. Clin. Pediatr. Neonatol.2019;7(1):1-4.

DOI: dx.doi.org/10.21276/ajcpn.2019.7.1.1

Source of Support: Nil, Conflict of Interest: None declared.
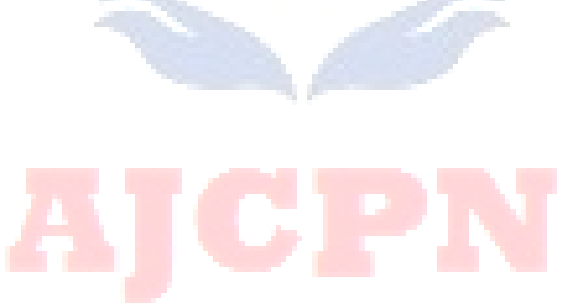